\title{
Pânico moral e ideologia de gênero articulados na supressão de diretrizes sobre questões de gênero e sexualidade nas escolas
}

\author{
RAFAELA OLIVEIRA BORGES \\ Universidade Federal de Santa Maria, Santa Maria, RS, Brasil
}

ZULMIRA NEWLANDS BORGES Universidade Federal de Santa Maria, Santa Maria, RS, Brasil

\section{RESUMO}

Este artigo se propõe, a partir de uma abordagem das ciências sociais, a analisar as condições que possibilitaram as supressões de diretrizes sobre questões de gênero, identidade de gênero e orientação sexual dos planos estadual e municipal de educação do Rio Grande do Sul e da sua capital, Porto Alegre. Tomando os mass media como espaços de visibilidade capazes de criar acontecimentos nas consciências dos atores sociais, busca-se analisar os argumentos e conteúdos divulgados por meio dos jornais e suas influências sobre tais supressões. A partir da Análise de Conteúdo identificamos os atores e argumentos colocados em ação na construção de um pânico moral em torno da categoria acusatória da "ideologia de gênero". Por fim, busca-se problematizar tal categoria que culmina com as pequenas, mas significativas, alterações nos planos de educação.

\section{PALAVRAS-CHAVE}

políticas públicas de educação; ideologia de gênero; pânico moral; empresários morais. 


\title{
MORAL PANIC AND GENDER IDEOLOGY ARTICULATED IN THE SUPPRESSION OF GUIDELINES ON GENDER AND SEXUALITY ISSUES IN SCHOOLS
}

\begin{abstract}
Coming from a social science approach, this article aims to analyze the conditions that allowed the suppression of guidelines on gender, gender identity and sexual orientation issues in the state and municipal educational plans of Rio Grande do Sul and its capital city, Porto Alegre. Understanding the media as a space of visibility that is able to create events in the consciousness of social actors, we seek to analyze the arguments and contents disseminated through newspapers and their influence on such suppressions. Using the content analysis method we identified the actors and arguments put into action in creating moral panic around the accusatory category of "gender ideology". Finally, we seek to problematize this category, and address small but significant changes in education plans.
\end{abstract}

KEYWORDS

public policy education; gender ideology; moral panic; moral entrepreneurs.

\section{PÁNICO MORAL Y IDEOLOGÍA DE GÉNERO ARTICULADOS EN LA SUPRESIÓN DE LAS DIRECTRICES SOBRE CUESTIONES DE GÉNERO Y SEXUALIDAD EN LAS ESCUELAS}

\section{RESUMEN}

Este artículo se propone, a partir de un enfoque de las ciencias sociales, el análisis de las condiciones que permitieron la eliminación de las directrices sobre las cuestiones de género, identidad de género y orientación sexual de los planes de educación estatal y municipal de Rio Grande do Sul, y su capital, Porto Alegre. Teniendo los mass media como espacios de visibilidad capaces de crear eventos en la conciencia de los actores sociales, tenemos por objetivo, analizar los argumentos y contenidos difundidos en los periódicos y sus influencias en esas supresiones. A partir del análisis de los contenidos identificó a los actores y argumentos en acción en la construcción de un pánico moral en torno a la categoría de acusación de "ideología de género". Por último, busca problematizar esta categoría que culmina con cambios pequeños pero significativos en los planes de educación.

\section{PALABRAS CLAVE}

políticas públicas de educación; ideología de género; pánico moral; empresarios morales. 


\section{INTRODUÇÃO}

Os planos de educação dos estados e municípios brasileiros formam um conjunto de estratégias que visam a articular políticas públicas educacionais, conforme demandas específicas de cada região. Para a formulação ou adequação desses planos educacionais, usa-se como referência o Plano Nacional de Educação $(\mathrm{PNE})^{1}$, pois constitui-se como matéria-base. Nesse sentido, o PNE reúne diretrizes e metas para a educação brasileira, com a expectativa de serem alcançadas no decorrer da década de 2014 a 2024.

As diretrizes que estruturam os planos educacionais resumem-se em quatro eixos, como a "garantia do direito a educação básica, redução das desigualdades e valorização da diversidade, valorização dos profissionais da educação e metas para o ensino superior ${ }^{2}$. Por meio das Conferências Nacionais de Educação (CONAEs) ${ }^{3}$, afirma-se que muitas deliberações resultaram em referenciais na implementação da lei que institui o plano-base para a educação nacional. Entretanto, enquanto projeto de lei, o PNE sofreu alterações por intermédio de emendas, também no eixo sobre "redução das desigualdades e valorização da diversidade", incluindo-se aí as questões de gênero e sexualidade. Assim, em momentos de aprovação do PNE, puderam ser acompanhadas votações paradoxais durante a tramitação da matéria no Congresso Nacional, entre 2011 e 2014, resultando na modificação do enfoque anterior, de promoção da "igualdade racial, regional, de gênero e de orientação sexual", para "cidadania e na erradicação de todas as formas de discriminação".

A mudança no eixo da redução das desigualdades desencadeou o início de uma polêmica que durou meses. Nesse cenário e como um efeito dominó, no final do primeiro semestre de 2015, data limite para formulações/adequações dos demais planos, assistiu-se pela mídia à retirada maciça, em diversos planos estaduais e municipais de educação, de questões relativas a gênero e sexualidade, reacendendo a polêmica sobre a inclusão dessas questões em plenários de câmaras municipais e assembleias legislativas do Brasil.

Diante de tal contexto, a finalidade deste artigo é discutir o delineamento de políticas públicas na educação brasileira que articulam as temáticas de gênero e sexualidade, tendo como objeto de estudo o plano estadual de educação do Rio Grande do Sul e o plano municipal de educação da capital gaúcha, Porto Alegre. Nesse sentido, o objetivo desta pesquisa é analisar as condições que possibilitaram a retirada de diretrizes sobre questões de gênero e sexualidade dos planos de educação em análise, bem como apontar alguns dos possíveis efeitos de tais supressões.

Para isso, como método de investigação, utiliza-se a Análise de Conteúdo, examinando-se as discussões em torno do tema a partir de quatro jornais on-line:

1 Lei n. 13.005, de 25 de junho de 2014. Aprova o Plano Nacional de Educação - PNE e dá outras providências. Disponível em: <http://www.planalto.gov.br/CCIVIL_03/_ Ato2011-2014/2014/Lei/L13005.htm>. Acesso em: 17 maio 2016.

2 PNE em Movimento. Disponível em: <http://pne.mec.gov.br >. Acesso em: 7 set. 2016.

3 Conferência Nacional de Educação (CONAE) 2014 - Documento Final. Disponível em: <http://fne.mec.gov.br/images/doc/DocumentoFina240415.pdf>. Acesso em: 17 maio 2016. 
Correio do Povo, G1, Sul 21 e Zero Hora. Os principais resultados mostram uma forte polarização entre argumentos de grupos religiosos e políticos da bancada religiosa contra os de políticos de partidos como PSOL, PCdoB, PT, professores e ativistas do movimento social LGBT. Os debates giraram em torno da categoria acusatória da "ideologia de gênero" religiosos divulgaram crenças em torno da ameaça de um incentivo à homossexualidade, uma livre escolha sobre o gênero, a destruição da família tradicional e dos conceitos de homem e mulher, ressaltando-se, a partir dessas concepções, um recorrente estado de pânico moral e constantes mobilizações sobre a presença das questões de gênero e sexualidade nos planos de educação.

Portanto, este artigo se inicia apresentando modificações ocorridas nos planos de educação em análise $\mathrm{e}^{5}$. Na sequência identificamos a polêmica, seus atores principais e investigamos suas teses. Em seguida, busca-se examinar o surgimento de um estado de pânico moral, problematizando seu argumento central, ou seja, a "ideologia de gênero". Apontamos a importância da contextualização social e histórica das construções de gênero e sexualidade. Por fim, nas considerações finais refletimos sobre os impactos mais concretos da política de aversão e medo às abordagens de gênero e sexualidade nas escolas.

\section{OS PLANOS DE EDUCAÇÃO}

O art. $8^{\circ}$ da lei n. 13.005/2014, que aprova o PNE, dispõe:

Art. $8^{\circ}$. Os Estados, o Distrito Federal e os Municípios deverão elaborar seus correspondentes planos de educação, ou adequar os planos já aprovados em lei, em consonância com as diretrizes, metas e estratégias previstas neste PNE, no prazo de em 1 (um) ano contado da publicação desta lei. (Brasil, 2014a)

Com efeito, o desenvolvimento de um plano-base para a educação expressa a intenção em articular formas de colaboração no sistema de ensino brasileiro. Tal iniciativa busca promover melhorias na educação e empreender, para isso, uma atualização e reformulação das políticas públicas na área. Nesse sentido, segundo o Ministério da Educação (MEC):

Elaborar um plano de educação no Brasil, hoje, implica assumir compromissos com o esforço contínuo de eliminação de desigualdades que são históricas no País. Portanto, as metas são orientadas para enfrentar as barreiras para o acesso

4 Conforme Furlani (2016, p. 2), “o termo 'ideologia de gênero’ não está presente, não é de uso no contexto das teorias de gênero. Esse termo, essa expressão, foi criada/inventada, recentemente, no interior de alguns discursos religiosos. Trata-se de uma interpretação equivocada e confusa, que não reflete o entendimento de 'gênero' presente na Educação e na escolarização brasileiras, nas práticas docentes e/ou nos cursos de formação inicial e continuada de professores/as" (grifos do original).

5 Vale ressaltar que este artigo se insere em uma pesquisa maior sobre a inclusão dos temas de gênero e sexualidade nas escolas com estudantes de licenciatura. 
e a permanência; as desigualdades educacionais em cada território com foco nas especificidades de sua população; a formação para o trabalho, identificando as potencialidades das dinâmicas locais; e o exercício da cidadania. A elaboração de um plano de educação não pode prescindir de incorporar os princípios do respeito aos direitos humanos, à sustentabilidade socioambiental, à valorização da diversidade e da inclusão e à valorização dos profissionais que atuam na educação de milhares de pessoas todos os dias. (Brasil, 2014b, p. 9, grifos nossos)

No entanto, com o precedente de supressões sofridas pelo texto do PNE, no que se refere ao enfoque da "redução das desigualdades e valorização da diversidade", excluindo-se do texto as questões de gênero e sexualidade, viu-se repetir como um efeito dominó, no final do primeiro semestre de 2015, a retirada maciça de questões relativas a gênero e sexualidade de diversos planos estaduais e municipais de educação. Desse modo, busca-se evidenciar as condições e os atores que levaram a afetar os planos estaduais e municipais, do Rio Grande do Sul e da sua capital, Porto Alegre.

Dada a constatação, mapearam-se os projetos de lei do Plano Estadual de Educação do Rio Grande do Sul (PEE-RS) e do Plano Municipal de Educação de Porto Alegre (PME-POA, atentando-se especificamente às palavras-chave gênero, identidade de gênero e orientação sexual ${ }^{6}$. Em seguida, compararam-se as diretrizes e metas iniciais constantes nos projetos de lei com as leis sancionadas desses dois planos educacionais. Procurou-se, assim, delimitar as mudanças que de fato ocorreram nos planos analisados.

Feito isso, pode-se afirmar que, de forma geral, tais diretrizes e metas encontradas nos projetos de lei centravam-se em criar políticas educacionais de modo a promover o acesso e o combate à evasão escolar por preconceito e discriminação de gênero, identidade de gênero e orientação sexual; fomentar cursos para a formação complementar ou inicial dos professores nas temáticas de gênero e sexualidade; assim como desenvolver espaços de discussão e materiais didáticos ao alcance de alunos, comunidade familiar e professores sobre a temática. Com tais intentos, objetivava-se a redução das desigualdades, a valorização da diversidade e o combate às discriminações nas escolas (Rio Grande do Sul, 2014).

O Quadro 1 exemplifica uma dessas metas e mostra como ela está inserida hoje nas leis dos planos educacionais em questão. ${ }^{7}$

Nas leis dos planos de educação, encontram-se hoje, no PEE-RS, somente duas metas com referências a gênero - e nenhuma sobre identidade de gênero. Sobre gênero, a meta 8.10 refere-se à "realização de oficinas para professores abordando temas contemporâneos como gênero e sexualidade, auxiliando assim no enfrentamento dos preconceitos" (Rio Grande do Sul, 2015). E a meta 8.12, conforme a lei n. 14.705/2015, aponta:

6 Identificou-se que essas categorias foram alvo de supressões e/ou modificações, também, nos planos de que tratamos (Rio Grande do Sul e Porto Alegre). Diante disso, tornaram-se as palavras-chave no mapeamento das modificações entre os projetos de lei e as leis sancionadas.

7 É importante ressaltar que foram inúmeras modificações, as quais não podem aqui ser descritas na integralidade, por questão de espaço. Portanto, será destacado apenas um exemplo. 
Quadro 1 - Plano Estadual de Educação - projeto de lei e lei aprovada.

\begin{tabular}{|c|c|}
\hline Projeto de lei n. 287/2014 (PEE) & Lei n. 14.705/2015 (PEE) \\
\hline $\begin{array}{l}\text { 8.35 Desenvolver, a partir da aprovação deste PEE-RS, políticas para } \\
\text { os alunos gays, lésbicas, bissexuais, travestis e transexuais e com HIV/ } \\
\text { AIDS, excluídos do sistema de ensino, criando um ambiente social } \\
\text { mais favorável e com equidade, no qual a escola seja um espaço em } \\
\text { que as discussões sobre gênero, sexualidade e epidemia de aids façam } \\
\text { parte do cotidiano de modo a minimizar toda forma de evasão ou a } \\
\text { exclusão por motivo de discriminação sexual e de gênero, promovendo } \\
\text { ações que favoreçam a autoestima e a autoimagem dessa população, } \\
\text { com enfoque no processo cultural, histórico e social, para que se possa } \\
\text { discutir a formação das identidades sexuais e a história da epidemia } \\
\text { de aids no Brasil. (Rio Grande do Sul, 2014, p. 25, grifos nossos) }\end{array}$ & $\begin{array}{l}\text { 8.31 Desenvolver, a partir } \\
\text { da aprovação deste PEE, } \\
\text { políticas para os excluídos do } \\
\text { sistema de ensino, criando um } \\
\text { ambiente social mais favorável } \\
\text { e com equidade minimizando } \\
\text { toda a forma de evasão ou } \\
\text { exclusão por motivo de qualquer } \\
\text { discriminação. (Rio Grande do } \\
\text { Sul, 2015, p. 29, grifos nossos) }\end{array}$ \\
\hline
\end{tabular}

Fontes: projeto de lei n. 287/2014 e lei n. 14.705/2015.

8.12 Promover condições, em regime de colaboração entre Seduc, Secretarias Municipais de Educação, instituições de ensino superior e mantenedoras de instituições privadas, à elaboração de propostas curriculares que incluam como temas transversais as questões de inclusão, direitos humanos, etnias, gênero e sexualidade, de modo a estimular as discussões sobre formas de superar as discriminações e os preconceitos. (Rio Grande do Sul, 2015, p. 27)

Ainda no PEE-RS, as poucas menções à orientação sexual aparecem acompanhadas da palavra respeito, ou seja, respeitando orientação sexual, raça, religião etc., mas já não mencionam o estudo sobre gênero e sexualidade. Já no PME-POA, enquanto lei, foram suprimidas das diretrizes e metas todas as menções sobre gênero, identidade de gênero e orientação sexual. Por conseguinte, tal mapeamento chama a atenção para algumas questões. Verifica-se que as discussões sobre gênero e sexualidade se encontram suprimidas e deslegitimadas nos planos educacionais; em grande medida, o mesmo ocorre com a discussão sobre a história da epidemia do HIV/AIDS.

A Associação Brasileira Interdisciplinar de AIDS (ABIA) tem empreendido a discussão sobre os desafios para o enfrentamento da epidemia de HIV/AIDS no Brasil atual. Em recente estudo, o contexto de crise político-econômica vivenciado pelo país é relacionado à constatação de que o Brasil, "outrora modelo para o mundo na resposta à epidemia do HIV e da AIDS, em 2016, caminha em retrocesso". Tal análise crítica da conjuntura político-econômica do país problematiza o retrocesso evidenciado na questão do enfrentamento da epidemia do HIV/AIDS.

Sobre isso, Seffner e Parker (2016) sugestionam propostas para superar um dos pontos deste retrocesso, constatado como o avanço do conservadorismo

8 Os grifos em itálico são das autoras. Observe-se que vimos aqui a retirada não apenas da discussão sobre gênero e sexualidade, mas sobre a história da epidemia da AIDS.

9 Mito vs Realidade: sobre a resposta brasileira à epidemia de HIV e AIDS em 2016. Disponível em: <http://abiaids.org.br/wp-content/uploads/2016/07/Mito-vs-Realidade_HIV-e-AIDS_BRASIL2016.pdf>.Acesso em: 26 jul. 2016. 
político-religioso sobre o assunto, o que resulta na redução da ênfase histórica dos Direitos Humanos nas discussões sobre gênero, sexualidade e a epidemia da AIDS. Segundo os autores, as perspectivas atuais sobre a epidemia da AIDS, nas “estratégias neoliberais", encontram-se pautadas sob o viés da medicalização. Assim, ao pensarem possibilidades para o enfrentamento da AIDS, Seffner e Parker (2016, p. 24-25) afirmam a importância, diante do contexto atual, de se "relacionar dados biomédicos da doença com ações que se ocupam do fenômeno de ordem político/social, que não apenas 'atravessam', mas que, efetivamente, constituem o que conhecemos como aids". Os autores apontam a situação paradoxal vivenciada pelo Brasil:

O país vive um duplo movimento: desperdício da experiência histórica acumulada no enfrentamento da aids, e uma situação de "fazer viver e deixar morrer", ou seja, propiciar que se possa viver pela oferta massiva de teste e tratamento e, ao mesmo tempo, deixar morrer por conta do recrudescimento dos processos de estigma, discriminação, violência social de toda ordem. (Seffner e Parker, 2016, p. 30)

De certo modo, esse "deixar morrer" de perspectivas vinculadas à ótica dos Direitos Humanos nas questões que envolvem gênero e sexualidade pode ser identificado nesse processo de alteração dos planos educacionais e que, em última instância, tem efeitos na saúde e na vida das pessoas, já que o descaso com a prevenção piora a saúde e reforça a violência. Assim, voltando-se à educação, a ênfase na formação de professores, como estava originalmente pensada, contribuiria para que a discussão sobre essas questões nas escolas desconstruísse preconceitos que se tornam nocivos e dificultam também o enfrentamento atual da epidemia do HIV/AIDS.

Por sua vez, as supressões verificadas tornam o texto do PEE-RS generalizante, restando a ênfase na "superação de discriminações", entretanto sem citar discriminações de gênero e identidade de gênero. A crítica recai também no fato de que manter no texto do PME-POA a busca por superação de preconceitos, tais como "do machismo, do sexismo, da homofobia, da lesbofobia, da transfobia", torna-se insuficiente, na medida em que se restringe a informação, o estudo e a discussão sobre gênero, sexualidade e se retira dos planos a história da epidemia da AIDS (Porto Alegre, 2015).

Logo, a problematização do avanço de perspectivas conservadoras, como desenvolvem Seffner e Parker (2016) na análise sobre a resposta brasileira ao enfrentamento da epidemia do HIV/AIDS, é desenvolvida no decorrer deste artigo no que tange à educação, com foco nos atores políticos, religiosos e sociais, e o contexto atual em que se formulam os planos de educação brasileiros. Diante do movimento conservador crescente, os autores frisam o "recuo nas políticas públicas de gênero e sexualidade" (Seffner e Parker, 2016, p. 29).

Diante disso, é relevante a investigação de uma onda conservadora que atua em diferentes esferas da vida social. No caso da educação, questionar posicionamentos e ações de diferentes atores, sejam eles políticos, religiosos, sociais, para além de verificar influências e recuos sobre os planos educacionais, problematiza a obstinação de certos setores conservadores da sociedade em ocultar discussões sobre gênero e sexualidade. 


\section{METODOLOGIA}

Utilizou-se o método da Análise de Conteúdo, que, de acordo com Bardin (1977, p. 31), "é um conjunto de técnicas de análise das comunicações". Para a autora, "a análise de conteúdo, enquanto método, torna-se um conjunto de técnicas de análise das comunicações que utiliza procedimentos sistemáticos e objetivos de descrição do conteúdo das mensagens" (Bardin, 1977, p. 38).

$\mathrm{O}$ banco de dados e fontes parte de um conjunto de reportagens publicadas no período de junho, julho e agosto de 2015, extraídas de quatro jornais on-line que abrangem o estado do Rio Grande do Sul e sua capital, Porto Alegre, o enfoque de momento: Correio Povo, G1, Sul 21 e Zero Hora.

Nessa perspectiva de análise e conjuntamente à revisão bibliográfica acerca dos estudos sobre gênero e sexualidade, base para interpretação e inferência dos dados da pesquisa, buscou-se, como aponta Bardin (1977, p. 9), analisar as mensagens por uma "dupla leitura, onde uma segunda leitura se substitui à leitura normal, do leigo". Em outras palavras, prestar-se, sobretudo, a "desocultação, no esforço de interpretar o não dito" ou o equivocado (Bardin, 1977, p. 9).

Destaca-se que, por se tratar de uma pesquisa das ciências sociais e ainda não haver uma resolução clara e específica que contemple as demandas e particularidades éticas da área de ciências humanas, e também por se tratar de uma pesquisa bibliográfica cujas fontes são de domínio público, estando disponíveis na internet, decidiu-se por não submetê-la a um comitê de ética. Entretanto, quando nos jornais aparecem falas de políticos, optou-se por preservar o anonimato.

\section{A POLÊMICA E OS JORNAIS}

Buscando analisar de modo detalhado as supressões nos planos educacionais, convém atentar-se, antes, ao contexto que antecedeu as votações dos planos educacionais, no qual se podem acompanhar movimentações relevantes por parte de setores conservadores da sociedade, liderados, em sua maioria, por grupos religiosos e políticos de bancadas religiosas. Esses atores alertavam contra o perigo da instalação e consolidação, do que eles chamaram, de uma "ideologia de gênero" nas escolas. Tais grupos espalharam muitos vídeos pela internet, por páginas em redes sociais ${ }^{10}$ e blogs, divulgando informações deturpadas e alarmistas sobre a inclusão das questões de gênero e sexualidade nos planos de educação.

Em Porto Alegre, as movimentações contra as questões de gênero e sexualidade no PME deram-se principalmente por meio do posicionamento contrário da Igreja católica sobre a questão; de forma similar, no PEE-RS, os deputados que

10 A disseminação de conteúdos sobre os perigos da "ideologia de gênero" pode ser conferida em vídeos disponíveis no site YouTube e em páginas da rede social Facebook, por exemplo: Ideologia de gênero: saiba o que é e rejeite essa ideia, disponível em: <https:// www.youtube.com/watch?v=9B9BU0QSCFk>, acesso em: 27 nov. 2015; e Brasil sem - Ideologia de gênero, disponível em: <https://www.facebook.com/brasilsemideolo giadegenero/?fref=ts>. Acesso em: 27 nov. 2015. 
também movimentaram a polêmica trabalharam em emendas para a retirada das questões de gênero e sexualidade nos planos educacionais e, como em muitos outros casos ocorridos em plenárias brasileiras, posicionaram-se em conformidade com a perspectiva religiosa ${ }^{11}$.

Destacam-se, a seguir, argumentações públicas com o posicionamento dos políticos e instituições sobre a questão; busca-se, assim, demonstrar o cenário e os atores envolvidos. Cabe ressaltar que os argumentos encontrados nas discussões, no que se refere aos dois planos de educação em análise, foram os mesmos.

No jornal Zero Hora, em 25 de junho de 2015, justifica um político: "É um tema que não pode ser imposto pelo Estado. Valores e escolhas sexuais devem ser ensinados pela família, não pela escola" (Kannenberg, 2015, s/p). Pontua o portal G1, em 19 de junho de 2015, posicionamento de um representante religioso:

Em primeiro lugar, a Igreja não quer impor suas ideias, quer propor um diálogo. Nós queremos uma educação inclusiva, mas um só detalhe que aparece no plano é sobre a questão da teoria ou ideologia de gênero, que anularia a diferença entre homem e mulher na escola. Como se a criança pudesse escolher se ela, apesar de ter um corpo de homem, pudesse ser mulher ou se tivesse um corpo de mulher pudesse ser homem. (G1 RS, 2015, s/p, grifos nossos)

Em contrapartida, o jornal Sul 21 parafraseia em seu informe, também no dia 19 de junho de 2015, manifestação da Associação Brasileira de Antropologia:

Evocando discursos religiosos, alguns parlamentares têm tratado como "ideologia" a consolidada reflexão científica brasileira e internacional que gira em torno da produção e reprodução de desigualdades sociais, que se justificam a partir de certas concepções normativas sobre gênero e sexualidade. Por isso, a entidade entende que o aprendizado a respeito das desigualdades de gênero, assim como das relacionadas à classe e raça, contribui de forma marcante para o conhecimento e enfrentamento das desigualdades históricas no país. (Fogliatto, 2015, s/p)

Partindo deste viés, Kannenberg (2015, s/p) relata a fala de uma vereadora defensora da manutenção da discussão de gênero: "Vai na contramão da história, é um retrocesso. Mantém a cultura do ódio, estimula o bullying e o preconceito LGBTs. E a escola, que deveria ser um espaço inclusivo e um espelho da sociedade, não reflete a diversidade que vivemos aqui fora. O plano aprovado é conservador e autoritário", conforme publicado pelo jornal Zero Hora, em 25 de junho de 2015.

$11 \mathrm{O}$ posicionamento público e contrário da Igreja Católica quanto à presença de diretrizes sobre questões de gênero e sexualidade nos planos educacionais foi notório em todo o Brasil. Em Porto Alegre, tal posicionamento deu-se por meio da Arquidiocese, que direcionou carta a políticos, pedindo a exclusão da temática, assim como seus bispos estiveram presentes em debates sobre a questão em telejornais, o que pode ser conferido no seguinte link: <http:/g1.globo.com/rs/rio-grande-do-sul/noticia/2015/06/igreja-critica-plano-de-educacao-que-trata-de-diversidade-de-genero-no-rs.html>. Acesso em: 26 jun. 2016. 
Com efeito, evidenciaram-se, nesta etapa da análise, argumentos que, além de terem sido recorrentes, influenciaram drasticamente as modificações dos planos de educação. Nessas perspectivas e sobre os conteúdos que pressupõem uma argumentação, afirma-se que os posicionamentos em favor das questões de gênero e sexualidade nas escolas demonstram entender que planos educacionais, ao buscarem o desenvolvimento de escolas inclusivas, com a "redução das desigualdades e a valorização da diversidade", não podem prescindir do estudo sobre gênero e sexualidade, pois estes são essenciais para o alcance de tal meta.

Por sua vez, os posicionamentos contra as diretrizes de gênero e sexualidade nos planos educacionais recaem em ideias de que, ao se discutir gênero e sexualidade, estar-se-ia induzindo a uma livre escolha ou a uma anulação das diferenças. $\mathrm{Na}$ realidade, observa-se nos estudos de gênero, segundo Louro (2001, p. 17), que diversas instâncias, em especial a escola, "exercitam uma pedagogia da sexualidade e do gênero e colocam em ação várias tecnologias de governo, esses processos prosseguem e se completam através de tecnologias de autodisciplinamento e autogoverno que os sujeitos exercem sobre si mesmos". Nesse sentido, aprendemos desde sempre como nos comportar, gesticular, movimentar e fazer uso de nossos corpos; tudo nos é ensinado, dentro e fora da escola. A questão é que, mesmo e apesar de tanto esforço normatizador, alguns escapam à lógica hegemônica e sofrem muito com isso. Sofrem bullying, discriminações, exclusões e violências variadas. A questão a ser observada é que os que defendem a retirada desses temas dos planos acabam sendo coniventes com a manutenção da violência existente.

A visão em torno de gênero e sexualidade adotada neste artigo é que esses aspectos da vida não têm uma causa única ou determinada, seja pela cultura e pela família, seja pela escola ou pela natureza. São processos complexos que perpassam construções sociais, culturais, familiares e históricas, bem como são efeitos de interações complexas entre esses aspectos e as questões biológicas.

O discurso sobre igualdade de gênero sempre tratou da igualdade das condições de gênero, que homens e mulheres tenham as mesmas condições para alcançar, dentre outras coisas, boa educação e salários justos, apesar das diferenças. Como diz o sociólogo Santos (2003, p. 56):

Temos o direito de ser iguais quando a nossa diferença nos inferioriza; e temos o direito de ser diferentes quando a nossa igualdade nos descaracteriza. Daí a necessidade de uma igualdade que reconheça as diferenças e de uma diferença que não produza, alimente ou reproduza as desigualdades.

De fato, temos de aprender que não importa de onde elas vieram ou como elas surgiram, as diferenças de gênero e sexualidade precisam ser discutidas na dimensão do respeito ao outro. Para a Antropologia, o que nos torna humanos são nossas diferenças, somos sempre diferentes e estamos sempre nos diferenciando e buscando formas de diferenciação - faz parte da criatividade humana e das construções históricas e culturais. Por isso, o que realmente deveria importar é a educação para o diálogo e a compreensão das diferenças, não apenas buscando 
entender como elas surgem ou como se estabelecem, mas proporcionando formas de convívio com igualdade de condições e sem discriminações.

No entanto, além das interpretações equivocadas, esses grupos e políticos religiosos sobrepõem também a perspectiva de que a "família é a instituição educadora por excelência”. Em tal perspectiva, a presença das questões de gênero e sexualidade nos planos educacionais acabaria por agredir a liberdade da família em educar crianças e adolescentes conforme suas convicções; nesse caso, educação religiosa, moral e sexual é vista como dever da família.

Viu-se eclodir, no seio das discussões em torno da polêmica, a máxima "Escola alfabetiza e família educa". Essa ideia, difundida pelos atores políticos/religiosos, acarretou emenda ao texto do PME-POA, no art. $2^{\circ}, \mathrm{XI}$, o qual determina a "valorização da família como o mais importante meio de educação na formação e na estruturação da sociedade" (Porto Alegre, 2015, p. 2).

Sobre essa "valorização da família", surge como questionamento o fato de que tais setores conservadores da sociedade vêm levantando bandeiras em prol do que se denominou família tradicional brasileira, caracterizada como heteronormativa e cristã - reforçando tal concepção de família, está em discussão o projeto de lei n. 6.583/2013, que dispõe sobre o Estatuto da Família.

O projeto de lei n. 6.583/2013, que se encontra em tramitação na Câmara dos Deputados, dispõe sobre os "direitos da família, e as diretrizes das políticas públicas voltadas para a valorização e apoiamento à entidade familiar”. Porém esse projeto se caracteriza como excludente, pois é reconhecido como família apenas o "núcleo social formado a partir da união entre um homem e uma mulher, por meio de casamento ou união estável, ou ainda por comunidade formada por qualquer dos pais e seus descendentes" 12 .

Diante desse fato, não menos polêmico do que as supressões sofridas pelos planos educacionais, o Estatuto da Família configura-se, para muitos, como um projeto de lei discriminatório e preconceituoso. Com o conceito de família descrito, percebe-se a desconsideração completa de outros arranjos familiares, presentes na realidade social.

Em contraponto a isso, sabe-se que, em 2011, o Supremo Tribunal Federal ${ }^{13}$ passou a reconhecer a união homoafetiva no Brasil, o que recai em direitos para a constituição de família, por exemplo. Nesse sentido, afirma-se:

Cada vez mais as políticas públicas são vinculadas à aquisição de direitos, daí a necessidade percebida por nós de enfatizar as mudanças nos direitos referentes a questões que envolvam família. Se a definição de políticas públicas que contemplem a família envolve o reconhecimento legal da existência de entidades familiares, em contrapartida a mudança das definições jurídicas é parte das mudanças nos ideários sociais que alimentam novos modelos de família reconhecidos como legítimos. (Itaboraí, 2005, p. 8)

12 Disponível em: <http://www.camara.gov.br/proposicoesWeb/prop_mostrarintegra?co dteor=1159761\&filename=PL+6583/2013>. Acesso em: 27 jun. 2016.

13 Supremo reconhece união homoafetiva. Disponível em: <http://www.stf.jus.br/portal/ cms/verNoticiaDetalhe.asp?idConteudo=178931>. Acesso em: 27 jun. 2016. 
Do mesmo modo e sobrepondo-se ao padrão hegemônico de família resumida em laços biológicos, frisa Itaboraí $(2005$, p. 8$)$ sobre a "emergência da noção de parentesco socioafetivo, pois este ajuda a desbiologizar os laços familiares".

Diante disso, é fato também que argumentos dos grupos religiosos e atores políticos/religiosos influenciaram diretamente as supressões e/ou as modificações sofridas pelos planos de educação, demonstrando a eficácia das pressões políticas advindas desses setores conservadores/religiosos da sociedade sobre a educação ${ }^{14}$.

Observa-se, nos trechos anteriores, a eficácia desses discursos acionados pelos setores tradicionais e religiosos da sociedade: com o discurso da "ideologia de gênero" e a "família tradicional brasileira", eles atingem pontos nevrálgicos da cultura brasileira e, por isso, geraram um "acontecimento" social, um fenômeno que mobilizou emocionalmente pessoas leigas que não estavam diretamente envolvidas e que não dominavam os elementos envolvidos na discussão, mas foram contaminadas por um medo crescente da destruição da família e de seus valores mais tradicionais.

Herzlich e Pierret (2005, p. 74) demonstram as particularidades que "decorrem do tratamento dado a um acontecimento por cada jornal":

Em particular, a imprensa escrita e audiovisual forma um sistema: cada mídia tem uma posição específica, remetendo a uma estratégia de redação própria, ela mesma determinada por imperativos econômicos, organizacionais, técnicos e também por normas sociais e funcionamentos ideológicos. É daí que decorre o tratamento dado a um acontecimento por cada jornal.

Nesse sentido, é significativo que por meio dos mass media - jornais, telejornais, internet - disseminaram-se discursos afirmativos sobre a "ideologia de gênero", o que nos leva a enfatizar, conforme Herzlich e Pierret (2005, p. 74), "o papel fundamental da comunicação de massa: o de criar um acontecimento na consciência dos atores sociais e, mais amplamente, o de cristalizar as relações que se instauram a seu respeito". Sendo assim, observa-se a importância desses veículos de comunicação na criação do acontecimento que seria "o perigo da ideologia de gênero" nos planos educacionais.

\section{OS EMPRESÁRIOS MORAIS DA IDEOLOGIA DE GÊNERO}

Analisando-se os jornais, verificou-se a "ideologia de gênero" como influenciadora direta nas supressões sofridas pelos planos educacionais em questão. Assim,

14 Cabe ressaltar que nas reportagens analisadas não se encontrou espaço significativo para argumentos de professores e ativistas do movimento social LGBT sobre a questão; tais posicionamentos são praticamente inexistentes. Porém no site YouTube e na rede social Facebook acompanhou-se a movimentação desses atores sociais: $F a$ cebook - Coletivo LGBT Cores (Nós precisamos do debate de gênero nas escolas), disponível em: <https:/www.facebook.com/coletivolgbtcores/photos/?tab=album\&album_ $\mathrm{id}=1114264901935279>$, acesso em 2 jul. 2016; e Religiosos XLGBT-Ensino de Gênero - Póe na Roda, disponível em: <https://www.youtube.com/watch?v=ZNXcxoxPyeM>, acesso em 29 jul. 2016; dentre outros. 
afirma-se, baseado na análise das argumentações e seus conteúdos advindos de grupos religiosos e atores políticos/religiosos, que tal expressão adverte sobre crenças resumidas em: "a ideologia de gênero quer acabar com a biologia"; "a ideologia de gênero quer excluir os conceitos de homem e mulher"; "a ideologia de gênero quer acabar com as famílias"; "a ideologia de gênero vai hipersexualizar as crianças e incentivar a homossexualidade”.

Com efeito, tais crenças são preocupantes, sobretudo, pelo fato de que estão equivocadas e traduzem interpretações livres de grupos religiosos e atores políticos/religiosos sobre a presença das questões de gênero e sexualidade nos planos educacionais. Entretanto a questão não é simplesmente constatar que existe uma interpretação religiosa equivocada sobre a questão, mas também o porquê da criação dessas crenças alarmistas, disseminadas por meio da categoria acusatória da "ideologia de gênero".

Buscando elucidar tal questão, sobre a criação de crenças ou mesmo regras, Becker (1977, p. 108) pontua que "as regras são produtos da iniciativa de alguém e podemos pensar nas pessoas que mostram tal iniciativa como empresários morais" ${ }^{15}$. Nesse sentido e sobre "os criadores de regras", afirma Becker (1977, p. 108, grifos nossos):

O protótipo do criador de regras, mas não a única variedade que veremos é o cruzado reformador. Ele se interessa pelo conteúdo das regras. As regras existentes não o satisfazem porque há algum mal que o perturba profundamente. Ele sente que nada pode estar certo no mundo até que as regras sejam feitas para corrigi-lo. Opera com uma ética absoluta; o que se vê é, sem restrição, total e verdadeiramente mal. Qualquer meio para eliminar esse mal é justificável.

Assim, pode-se afirmar que os grupos religiosos/conservadores, utilizando eficazmente os mass media, foram os atores que influenciaram a criação das novas regras dos planos educacionais. Com o intuito de salvaguardar a família tradicional brasileira, encontram o mal na inserção das questões de gênero e sexualidade nos planos educacionais; e, com a eficácia da disseminação da "ideologia de gênero", pretendem excluir, como verdadeiros "cruzados morais", o perigo iminente. Como diria Becker (1977, p. 108), "é adequado pensar nos reformadores como cruzados porque eles acreditam que sua missão é sagrada". No caso específico aqui tratado, essas figuras realmente se mesclam, já que os cruzados morais são realmente religiosos.

$\mathrm{O}$ autor ainda pontua que "o cruzado moral, em algum ponto do desenvolvimento de sua cruzada, muitas vezes exige os serviços de um profissional que possa estabelecer as regras apropriadas, de uma forma apropriada" (Becker, 1977, p. 112). Diante disso, há uma articulação eficiente entre os grupos religiosos, os meios de comunicação e os políticos de bancadas religiosas. Prossegue o autor:

A consequência mais óbvia de uma cruzada bem-sucedida é a criação de um novo conjunto de regras. Com a criação de um novo conjunto de regras, des-

15 Segundo Becker (1977, p. 109), os empresários morais estabelecem-se em "duas classes e estão relacionadas entre si - os criadores de regras e os impositores de regras”. 
cobrimos frequentemente que se estabelece um novo conjunto de agências e funcionários de imposição. (Becker, 1977, p. 114)

Dessa forma, o discurso que grupos religiosos construíram sobre a "ideologia de gênero" criou regras para motivar a exclusão das questões de gênero e sexualidade dos planos educacionais. Com efeito, a supressão e/ou modificação por meio de emendas das leis dos planos educacionais foram empreendidas pelos atores políticos/ religiosos, impondo, assim, essas novas regras e tornando a cruzada moral, como afirma Becker (1977, p. 114), "institucionalizada". Logo, a cruzada bem-sucedida, além de criar regras e impor novas leis, por exemplo, estabelece também um novo grupo marginalizado e tido como desviante. Quem é esse novo grupo? Todos aqueles que insistirem em discutir essas questões em sala de aula. Assim, o efeito lógico é a nova demanda desses grupos pela "escola sem partido".

Somado a isso, ressalta-se que a eficácia do discurso que adverte a "ideologia de gênero", difundido pelos mass media, deu-se, segundo Gomes (2013, p. 187), por "uma ênfase exagerada sobre o risco de vitimização, o que contribuiu para a construção de um estado de pânico moral".

Em linhas gerais, segundo Cohen (1987, p. 9 apud Machado,2004, p. 60-61), o pânico moral caracteriza-se como um conjunto de eventos que emergem em determinados momentos e são tomados como uma ameaça aos valores e interesses sociais; eles são apresentados de maneira estereotipada pelos mass media e barreiras morais se fortalecem contra o surgimento desta situação vista como ameaçadora. Nesse sentido, especialistas com algum respaldo social, como líderes políticos e religiosos, dentre outros, vêm a público manifestar seus diagnósticos e resoluções. Logo, estratégias de enfrentamento são criadas ou recorre-se às já existentes, até que a polêmica se esvazie e desapareça (Cohen, 1987 apud Machado, 2004).

É importante destacar que Cohen relaciona o processo em que se dá o pânico moral com as reações coletivas às catástrofes e nesse sentido reconhece, pelo menos, três fases, quais sejam, a "fase de inventário do problema, uma fase de significação e uma fase de ação" (Cohen, 1987 apud Machado, 2004, p. 61). Na fase do inventário do problema, a discussão ocorre nos mass media e traz à tona "um conjunto de rumores e percepções públicas desorganizadas”(Machado, 2004, p. 61). Sobre essa primeira fase, pontua a autora:

Neste processo, operam-se duas tarefas essenciais para a gênese do pânico moral: a constituição de um acontecimento como problema social e, por outro lado, a fixação de uma grelha interpretativa que estabelece o seu significado primário e parâmetros de interpretação, condicionando todas as notícias e interpretações subsequentes (nomeadamente, pela atenção selectiva aos acontecimentos que se coadunam com as previsões ou interpretações iniciais). Este enquadramento será, por sua vez, derivado de convenções preexistentes (tanto mais quanto mais ambíguo for o problema e mais incerto estiver o jornalista sobre o modo de o apresentar), conduzindo a um processo de relato que tende a ser reprodutor do senso comum. (Machado, 2004, p. 61) 
Nesse sentido, a primeira fase configura-se com os vídeos colocados em sites e blogs, alertando para o perigo da ideologia de gênero, como um problema social instituído na mídia. Por outro lado, a grelha interpretativa se estabelece nos jornais com as manifestações dos políticos religiosos, divulgando a referida categoria acusatória em que os planos estariam propondo uma doutrinação nova e nefasta para as crianças.

$\mathrm{Na}$ segunda fase, ocorre a significação do problema, na qual, segundo Machado (2004, p. 61), desenvolve-se a "mobilização de opiniões e atitudes deslocando a atenção do domínio factual para o domínio interpretativo ou do problema em si mesmo para as suas implicações e consequências". Aparecem aqui os riscos e efeitos caso os planos incluam gênero e sexualidade nas suas diretrizes, o "fim da família" e o "fim da identidade de gênero". Nesse sentido, ocorre o processo de "demonização, recorrendo-se a um conjunto de imagens preexistentes do mal, frequentemente condensadas em torno de grupos socialmente mais vulneráveis" (Machado, 2004, p. 62), o que confirma estereótipos iniciais veiculados pelos mass media. O trecho abaixo exemplifica o discurso daqueles que veem a "ideologia de gênero" como uma grande ameaça:

Ora, a ideologia de gênero sustenta que a pessoa humana é sexualmente indefinida e indefinível. Elimina-se a ideia de que os seres humanos se dividem em homem e mulher. Para além das evidências anatômicas, entendem que esta não é uma determinação fixa da natureza, mas resultado de uma cultura ou de uma época. Para a ideologia de gênero o "natural" não é tido como valor humano e é preciso superar até mesmo a distinção da natureza masculina e feminina das pessoas. Com o intuito de superar discriminações, desconsideram-se as diferenças. Acusa-se que as explicações naturais são formulações ideológicas para manter determinada posição social. Como consequência da questão de gênero, promove-se a desvalorização da família em favor da liberdade individual, desconsidera-se a maternidade natural e o matrimônio, e desprezam-se os valores religiosos. (Spengler, 2015, s/p, grifos nossos)

A imagem do mal é de que todas as crianças poderiam vir a se tornar transgêneros, já que a ideologia de gênero ensinaria que as fronteiras são cultural e socialmente construídas; consequentemente, isso acabaria com a família e os valores religiosos.

De acordo com Machado (2004), a fase de ação culmina em relacionar os níveis de sensibilização com a mobilização do controle social, objetivando este último, "o controle do desvio e, sobremaneira, tornam-se importantes os papéis de agências formais bem como dos 'empresários morais', que agem em nome da consciência e interesses coletivos" (Spengler, 2015, p. 62).

Dessa forma, o discurso alarmista da "ideologia de gênero", que se viu disseminar em meio à polêmica sobre as supressões sofridas pelos planos educacionais, gerou medo. Frisa Miskolci (2007, p. 114) que "o pânico moral fica plenamente caracterizado quando a preocupação aumenta em desproporção ao perigo real e gera reações coletivas também desproporcionais". 
Com efeito, a polêmica envolvendo as supressões das questões de gênero e sexualidade dos planos educacionais, na qual o argumento da "ideologia de gênero" é desencadeador de pânico moral, caracteriza-se pela fase do inventário do problema, em que os mass media veiculam discursos estereotipados sobre "ideologia de gênero". Ainda, a significação do problema e sua consequente cristalização reforçam tais discursos alarmistas, mobilizam opiniões polarizadas sobre a questão e acabam por intensificar uma movimentação relevante de setores conservadores/religiosos da sociedade, demonizando a inserção das questões de gênero e sexualidade nos planos educacionais.

Por fim, na fase de ação, regras são criadas; aos que transpassarem os padrões das normalidades, restará o título de desviante e culpabilizado pelos problemas sociais. Sobre esses problemas, como verdadeiros "empresários morais", grupos conservadores/religiosos e atores políticos/religiosos empreenderam juntos nas supressões sofridas pelos planos educacionais, resultando em leis, como verificado, sem questões de gênero e sexualidade. Tudo isso foi feito em vista de manter, por meio do controle social, a perspectiva de mundo religiosa e a manutenção de uma ordem social, que neste caso pode ser lida por ordem heteronormativa.

Logo, a criação de novas regras, acarretando na supressão das diretrizes sobre questões de gênero e sexualidade nos planos de educação em questão, foi possibilitada pelas "cruzadas" de grupos religiosos e atores políticos/religiosos. O estado de "pânico moral" realizou-se pela disseminação de crenças alarmistas em torno da "ideologia de gênero" e, portanto, tais constatações levam à observação de um retrocesso conservador na sociedade brasileira, em que vetar o estudo sobre a diversidade nas escolas é, sobretudo, a negação da existência da diversidade humana. Assume-se, assim, um desejo de retrocesso, tornando a escola um ambiente potencializador "do racismo, do machismo, do sexismo, da homofobia, da lesbofobia, da transfobia, da intolerância religiosa, do bullying e de toda forma de preconceito e discriminação" (Porto Alegre, 2015, p. 51-52).

\section{DESTRINCHANDO ARGUMENTOS QUE COMPÕEM A CATEGORIA ACUSATÓRIA DA IDEOLOGIA DE GÊNERO}

Frisa-se que o discurso que adverte a "ideologia de gênero" não possui nenhum dado de realidade, visto que não existe literatura que verifique o que se prega sobre essa expressão. Assim, os elementos descritos como pertencentes a uma "ideologia de gênero" foram criados por grupos religiosos; no caso do Rio Grande do Sul e de Porto Alegre, desempenharam papel atuante na afirmação desse discurso a Igreja católica e os políticos religiosos (católicos e evangélicos), utilizando-se da "ideologia de gênero" como categoria de acusação.

Pode-se perceber que questões em torno da sexualidade (reprodução/casamento) parecem, na maior parte do tempo, constituir a verdadeira preocupação da "ideologia de gênero", ao passo que as questões propriamente relacionadas a gênero acabam confusas numa mistura de pressupostos religiosos sobre as questões de gênero e sexualidade. Constata-se disso a base essencialista dos argumentos, em 
que o tratamento sobre sexo ${ }^{16}$, gênero e sexualidade se constitui numa sequência lógica e equivalente no cerne do discurso heteronormativo da "ideologia de gênero". Por esse prisma, Heilborn e Brandão (1999, p. 2) desenvolvem discussão acerca do debate contemporâneo no que se refere à sexualidade:

O olhar antropológico caracteriza-se, em particular, por tomar de maneira mais ou menos radical a afirmativa de que os temas a serem investigados fazem sentido somente a partir da teia de significados e relações sociais que os sustentam em um determinado contexto. Assim, o que é sexo para um certo grupo não é necessariamente para outro, e os nexos estabelecidos entre essa dimensão e as demais da vida social também variam [...].

Nesse ponto, faz sentido questionar as concepções engessadas sobre sexo, gênero e sexualidade encontradas no discurso da "ideologia de gênero". Assim, acerca das questões em torno da sexualidade, afirma Foucault (1999, p. 100):

A sexualidade é o nome que se pode dar a um dispositivo histórico: não à realidade subterrânea que se apreende com dificuldade, mas à grande rede de superfície em que a estimulação dos corpos, a intensificação dos prazeres, a incitação ao discurso, a formação dos conhecimentos, o reforço dos controles e das resistências, encadeiam-se uns aos outros, segundo algumas grandes estratégias de saber e de poder.

Adotando a perspectiva de que a sexualidade se inscreve como um "dispositivo histórico", explica-se, segundo Louro (2001, p. 11-12), que "ela é uma invenção social e constitui-se historicamente a partir de múltiplos discursos sobre o sexo, que regulam, normatizam e instauram saberes que produzem verdades".

Para uma análise crítica sobre esse cenário, é importante lembrar o que afirmam Heilborn e Brandão (1999, p. 2): "o debate teórico em torno da sexualidade tem sido marcado pelo enfrentamento entre duas posições: o essencialismo e o construtivismo social". Este último, de acordo com as autoras, tem a seguinte perspectiva:

De que existem formas culturalmente específicas, que o olhar ocidental chamaria de sexualidade, que envolvem contatos corporais entre pessoas do mesmo sexo ou de sexos diferentes, ligados ou não à atividade reprodutiva, que podem ter significados radicalmente distintos entre as culturas, ou mesmo entre grupos populacionais de uma determinada cultura. Portanto, os significados sexuais e, sobretudo, a própria noção de experiência ou comportamento sexual não seriam passíveis de generalização, dado que estão ancorados em teias de significados articuladas a outras modalidades de classificação, como o sistema de parentesco e de gênero, as classificações etárias, a estrutura de privilégios sociais e de distribuição de riqueza, etc. (Heilborn e Brandão, 1999, p. 3)

16 Neste caso, conforme Grossi (1998, p. 12, grifo do original) “sexo é uma categoria que ilustra a diferença biológica entre homens e mulheres". 
Em relação ao viés essencialista, Heilborn e Brandão (1999, p. 3) afirmam (que predomina a crença de que "há algo inerente à natureza humana, inscrito nos corpos como um instinto ou energia sexual que conduz as ações; a sexualidade ora restringe-se a um mecanismo fisiológico, a serviço da reprodução, ora à manifestação de ordem psíquica, que busca se extravasar”. Por sua vez, Weeks (2001, p. 43) contribui com esta reflexão:

O "essencialismo" é o ponto de vista que tenta explicar as propriedades de um todo complexo por referência a uma suposta verdade ou essência interior. Essa abordagem reduz a complexidade do mundo à suposta simplicidade imaginada de suas partes constituintes e procura explicar os indivíduos como produtos automáticos de impulsos internos.

É em torno dessa perspectiva "simplista" que se baseia o discurso da "ideologia de gênero", o qual, partindo de uma perspectiva essencialista, conjuntamente ao viés religioso, conforme Heilborn e Brandão (1999), reifica "determinados comportamentos e identidades sexuais". Assim, ao transpassar barreiras heteronormativas ou contrariar "marcas biológicas" (Louro, 2001), por força da norma, geram-se processos de estigma e desvio. Nesse aspecto, ressalta-se:

O reconhecimento do "outro", daquele ou daquela que não partilha dos atributos que possuímos, é feito a partir do lugar social que ocupamos e, então, constroem os contornos demarcadores das fronteiras entre aqueles que representam a norma que estão em consonância com seus padrões culturais e aqueles que ficam fora dela, às suas margens. Em nossa sociedade, a norma que se estabelece, historicamente, remete ao homem branco, heterossexual, de classe média urbana e cristão e essa passa a ser a referência que não precisa ser nomeada. Serão os "outros" sujeitos sociais que se tornaram "marcados", que se definirão e serão denominados a partir dessa referência. Desta forma, a mulher é representada como "o segundo sexo" e gays e lésbicas são descritos como desviantes da norma heterossexual. (Louro, 2001, p. 15-16)

Logo, as lógicas dos dois pensamentos - essencialismo e construtivismo se opõem. Essas diferentes perspectivas sobre como compreender a sexualidade humana evidenciam que existem outros horizontes que questionam o essencialismo (raiz do discurso acusatório da "ideologia de gênero"). As perspectivas construcionistas podem contribuir para a inclusão da discussão sobre diversidade, gênero, identidade de gênero e orientação sexual nas escolas.

\section{A IMPORTÂNCIA DA CONTEXTUALIZAÇÃO SOCIAL E HISTÓRICA DAS CONSTRUÇÕES DE GÊNERO E SEXUALIDADE NO COMBATE AOS EFEITOS DO PÂNICO MORAL}

Por conseguinte, constatou-se também, no discurso acerca da "ideologia de gênero", uma confusão sobre as categorias de gênero e sexualidade. Conforme Mott (2007, p. 21), "as análises transculturais provaram que sexualidade não determina papéis de gênero". Na lógica dessa afirmação, Grossi $(1998$, p. 12) frisa a importância 
de "desconstruir o senso comum ocidental que considera que a identidade de gênero é marcada pela opção sexual”. A autora complementa:

De uma forma simplificada, diria que sexo é uma categoria que ilustra a diferença biológica entre homens e mulheres; que gênero é um conceito que remete à construção cultural coletiva dos atributos de masculinidade e feminilidade (que nomeamos de papéis sexuais); que identidade de gênero é uma categoria pertinente para pensar o lugar do indivíduo no interior de uma cultura determinada e que sexualidade é um conceito contemporâneo para se referir ao campo das práticas e sentimentos ligados à atividade sexual dos indivíduos. (Grossi, 1998, p. 12)

Por fim, mas não menos importante, o gênero em si, pontua Scott (1995, p. 86), "é um elemento constitutivo de relações sociais baseadas nas diferenças percebidas entre os sexos e [...] o gênero é uma forma primária de dar significado às relações de poder". Nesse sentido, busca-se salientar a percepção social, cultural e histórica sobre as construções e representações acerca do gênero e sexualidade, tornando-se exemplar a afirmação de Mead (2003) sobre a "padronização do temperamento sexual", posto que:

Quando ponderamos o comportamento do típico homem ou mulher Arapesh, em contraste com o típico homem ou mulher Mundugumor, a evidência é esmagadoramente a favor do condicionamento social. De nenhum modo podemos dar conta da uniformidade quase completa que as crianças Arapesh se transformam em pessoas satisfeitas, passivas, seguras, enquanto que as crianças Mundugumor se convertem caracteristicamente em pessoas violentas, agressivas e inseguras. Só ao impacto do todo da cultura integrada sobre a criança em crescimento podemos atribuir a formação dos tipos contrastantes. Não há outra explicação de raça, dieta ou seleção que possamos aduzir para esclarecê-la. Somos forçados a concluir que a natureza bumana é quase incrivelmente maleável, respondendo acurada e diferentemente a condiçôes culturais contrastantes. [...] As padronizadas diferenças de personalidade entre os sexos são desta ordem criaçôes culturais às quais cada geração, masculina e feminina é treinada a conformar-se. (Mead, 2003, p. 268-269, grifos nossos)

Por conseguinte, afirma-se que, baseadas nas diferenças dos "sexos", muitas desigualdades entre mulheres e homens ganham significados no seio da sociedade, e os estudos sobre gênero propiciam, sobremaneira, o pensamento crítico sobre isso. Em outras palavras, Grossi (1998, p. 4) enfatiza que "essa explicação da ordem natural é uma formulação ideológica que serve para justificar os comportamentos sociais de homens e mulheres em determinada sociedade".

Portanto os estudos sobre gênero, como uma categoria analítica, atentam-se às desigualdades sociais e problematizam normas sobre a sexualidade, pois, como frisa Furlani (2016, p. 4), "nascemos com um sexo que nos define como homem e mulher". Entretanto, as questões de gênero, identidade de gênero e sexualidade propõem repensar o processo de significação desses corpos, a fim de, como propunham inicialmente os planos de educação, refletir, questionar e discutir questões que busquem a "redução das desigualdades e a valorização da diversidade". 


\section{CONSIDERAÇÕES FINAIS}

O avanço do movimento conservador/religioso sobre a educação no momento obteve eficácia graças ao pânico moral instaurado pela categoria acusatória da ideologia de gênero. Mas é preciso alertar para os possíveis efeitos do pânico moral e da retirada dos temas gênero e sexualidade das escolas, tais como: o risco de reforço da estigmatização e da discriminação das identidades de gênero e sexuais que escapam da norma, assim como o aumento da homofobia, da lesbofobia e da transfobia e outras formas de violências físicas ou simbólicas. Mas o aumento da evasão escolar e, consequentemente, da exclusão social desses sujeitos é certamente um dos efeitos mais incoerentes e divergentes para uma política de educação e escolarização. Nesse sentido, ironicamente, resta perguntar: como pode uma política educativa promover e reforçar a exclusão de alguns grupos sociais? Os parâmetros curriculares e as políticas educacionais não deveriam ter como objetivo ético, vital e primordial a adesão escolar e o estímulo à conclusão de toda a trajetória escolar para todos os estudantes? Não deveriam oferecer alguma atenção àqueles que mais sofrem com os mecanismos de exclusão social? Nesse sentido, um silenciamento sobre esses temas pode recolocar essas pessoas em uma situação de exclusão e invisibilidade em longo prazo, na qual nem a existência parece ser admissível.

Outro efeito importante e pouco discutido atinge justamente os/as que se enquadram na norma heterossexual e de gênero. A ausência de informações sobre doenças sexualmente transmissíveis (DST) e contracepção na escola assim como a restrição das redes de apoio e confiança que a escola ofereceria podem aumentar o risco de contaminação por HIV e da gravidez indesejada e, consequentemente, impactar negativamente os projetos de vida desses jovens.

$\mathrm{O}$ avanço conservador constatado aqui e verificado por Seffner e Parker (2016) na resposta brasileira à epidemia do HIV/AIDS demonstra o momento delicado em que o Brasil caminha em retrocesso. Porém pode-se pensar que avanços e retrocessos não se dão em linearidade na linha histórica, mas configuram momentos de idas e vindas. Nesse sentido, entende-se, conforme Seffner e Parker (2016, p. 32), que assim como é imprescindível o "respeito e autonomia para os atores sociais" efetivarem uma resposta de enfrentamento à epidemia da AIDS, é necessário intensificar o diálogo entre diferentes atores sociais. É essencial incluir não só os atores presentes no espaço escolar, como professoras, psicopedagogas, psicólogas, diretoras, intelectuais, mas também os demais atores envolvidos no tema, mobilizando a sociedade e seus diversos setores e movimentos em prol de uma sociedade mais justa e igualitária.

\section{REFERÊNCIAS}

Bardin, L. Análise de conteúdo. Lisboa: Edições 70, 1977.

Becker, H. S. Uma teoria da ação coletiva. Rio de Janeiro: Zahar, 1977. 
Brasil. Lei no 13.005 de 25 de junho de 2014. Aprova o Plano Nacional de Educação PNE e dá outras providências. Brasília: Presidência da República, 2014a. Disponível em: <http://www.planalto.gov.br/CCIVIL_03/_Ato2011-2014/2014/Lei/L13005. htm>. Acesso em: 8 nov. 2015.

. Ministério da Educação/Secretaria de Articulação com os Sistemas de Ensino. Planejando a próxima década: conhecendo as 20 metas do Plano Nacional de Educação. 2014b. Disponível em <http://pne.mec.gov.br/images/pdf/pne_conhecendo_20_metas. pdf>. Acesso em: 17 nov. 2015.

Fogliatto, D. Igreja pressiona contra Plano de Educação por abordar questões de gênero e sexualidade. Sul 21, Porto Alegre, 19 jun. 2015. Disponível em: <http://www. sul21.com.br/jornal/igreja-pressiona-contra-plano-de-educacao-por-abordar-questoesde-genero-e-sexualidade>. Acesso em: 18 set. 2015.

Foucault, M. História da Sexualidade I: a vontade de saber. Rio de Janeiro: Graal.1999. Furlani, J. Ideologia de gênero? Explicando as confusões teóricas presentes na cartilha. Versão Revisada 2016. Florianópolis: FAED, UDESC. Laboratório de Estudos de Gênero e Família, 2016. 9 p. Disponível em: <https://www.facebook.com/jimena. furlani/media_set?set=a.874615945993418.1073741831.100003350625907\&type=3 > . Acesso em: 31 jul. 2016.

G I RS. Igreja critica plano de educação que trata de diversidade de gênero no RS. G1, Porto Alegre, 19 jun. 2015. Disponível em: <http://g1.globo.com/rs/rio-grande-do-sul/ noticia/2015/06/igreja-critica-plano-de-educacao-que-trata-de-diversidade-de-generono-rs.html>. Acesso em: 18 set. 2015.

Gomes, S. A construção do pânico moral sobre os ciganos e os imigrantes na imprensa diária portuguesa. Latitude Revista, Maceió, p. 187-217, 2013. Disponível em: <http:// www.seer.ufal.br/index.php/latitude/article/view/1294>. Acesso em: 09 set. 2016

Grossi, M. P. Identidade de Gênero e sexualidade. Antropologia em Primeira Mão, Florianópolis, p. 1-18, 1998. Disponível em: <http://www.miriamgrossi.ch.prof.ufsc. br/pdf/identidade_genero_revisado.pdf $>$. Acesso em: 17 nov. 2015.

Heilborn, M. L.; Brandão, E. R. Introdução: Ciências Sociais e Sexualidade. In: Heilborn, M. L. (Org.). Sexualidade: o olhar das Ciências Sociais. Rio de Janeiro: Zahar, 1999. p. 7-17. Disponível em: <http://www.clam.org.br/bibliotecadigital/ uploads/publicacoes/108_1042_introducaocienciassociaisesexualidade.pdf > Acesso em: 18 set. 2016.

Herzlich, C.; Pierret, J. Uma doença no espaço público: a AIDS em seis jornais franceses. Physis: Revista de Saúde Coletiva, Rio de Janeiro, v. 15, supl., p. 71-101, 2005. Disponível em: <http://www.scielo.br/pdf/physis/v15s0/v15s0a05.pdf >. Acesso em: 3 nov. 2015.

ItABoraí, N. R. A proteção social da família brasileira contemporânea: reflexões sobre a dimensão simbólica das políticas públicas. In: Seminário “As Famílias e as Políticas Públicas no Brasil”, 2005, Belo Horizonte. Anais... Belo Horizonte: ABEP, 2005. Disponível em: <http://www.abep.nepo.unicamp.br/docs/anais/outros/FamPolPublicas/ NathalieItaborai.pdf>. Acesso em: 27 jun. 2016. 
Kannenberg, V. Com beijaço gay e manifestações, Plano Municipal de Educação é aprovado sem incluir identidade de gênero. Zero Hora, Porto Alegre, 25 jun. 2015. Disponível em:<http://zh.clicrbs.com.br/rs/noticias/noticia/2015/06/com-beijaco-gaye-manifestacoes-plano-municipal-de-educacao-e-aprovado-sem-incluir-identidadede-genero-4788316.html>. Acesso em: 18 set. 2015.

Louro, G. O corpo educado: pedagogias da sexualidade. Belo Horizonte: Autêntica, 2001. Machado, C. Pânico moral: para uma revisão do conceito. Interações, Coimbra, v. 7, p. 60-80, 2004.

Mead, M. Sexo e temperamento. São Paulo: Perspectiva, 2003.

Misкolci, R. Pânicos morais e controle social: reflexões sobre o casamento gay. Cadernos Pagu [on-line], n. 28, p. 101-128, 2007. Disponível em: <http://dx.doi.org/10.1590/ S0104-83332007000100006>. Acesso em: 20 nov. 2015.

Mотт, L. Antropologia, teoria da sexualidade e direitos humanos dos homossexuais. Bagoas: estudos gays - gênero e sexualidade, n. 1, p. 61-75, 2007. Disponível em: <http:// www.cchla.ufrn.br/bagoas/v01n01bagoas01.pdf\#page=61>. Acesso em: 20 nov. 2015.

Porto Alegre. Lei no 11.858 de 25 de junho de 2015. Institui o Plano Municipal de Educação. Porto Alegre: Câmara dos Vereadores de Porto Alegre, 2015. Disponível em:<http://www2.portoalegre.rs.gov.br/netahtm1/sirel/atos/Lei\%2011858>. Acesso em: 17 nov. 2015.

Rio Grande do Sul. Projeto de Lei no 287/2014. Poder Executivo institui o Plano Estadual de Educação - PEE, em cumprimento ao Plano Nacional de Educação PNE. Porto Alegre: Assembleia Legislativa do Estado do Rio Grande do Sul, 2014. Disponível em: $<$ http://www.al.rs.gov.br/legislativo/ExibeProposicao.aspx?SiglaTipo= PL\&NroProposicao=287\&AnoProposicao=2014>. Acesso em: 15 nov. 2015

Lei no 14.705 de 25 de junho de 2015. Institui o Plano Estadual de Educação - PEE em cumprimento ao Plano Nacional de Educação - PNE. Porto Alegre: Assembleia Legislativa do Estado do Rio Grande do Sul, 2015. Disponível em: <http:// www.al.rs.gov.br/filerepository/repLegis/arquivos/LEI\%2014.705.pdf>. Acesso em: 17 nov. 2015.

Santos, B. S. Reconhecer para libertar: os caminhos do cosmopolitanismo multicultural. Rio de Janeiro: Civilização Brasileira, 2003.

Scott, J. Gênero: uma categoria útil de análise histórica. Educação \& Realidade, Porto Alegre, v. 20, n. 2, p. 71-99, jul./dez. 1995.

SefFner, F.; Parker, R. A neoliberalização da prevenção do HIV e a resposta brasileira à AIDS. In: Associação Brasileira InTerdisciplinar de AIDS (ABIA) (Org.). Mitos vs. realidade: sobre a resposta brasileira à epidemia de HIV e AIDS em 2016. Disponível em: <http://abiaids.org.br/wp-content/uploads/2016/07/Mito-vs-Realidade_HIV-eAIDS_BRASIL2016.pdf $>$. Acesso em: 27 jul. 2016.

Spengler, J. Carta enviada pela arquidiocese de Porto Alegre para os vereadores. Zero Hora, Porto Alegre, 10 jun. 2015. Disponível em: <http://www.zerohora.com.br/ pdf/17465039.pdf>. Acesso em: 18 set. 2015. 
WeEks, J. O corpo e a sexualidade. In: Louro, G. L.(Org.). O corpo educado: pedagogias da sexualidade. Belo Horizonte: Autêntica, 2001.

\section{SOBRE AS AUTORAS}

Rafaela Oliveira Borges é mestranda em ciências sociais pela Universidade Federal de Santa Maria (UFSM).

E-mail: rafaelaoborges@hotmail.com

Zulmira Newlands Borges é doutora em antropologia social pela Universidade Federal do Rio Grande do Sul (UFRGS). Professora da Universidade Federal de Santa Maria (UFSM).

E-mail: zulmiraborges@gmail.com 